\title{
Ethanol absorption after gastric operations, and in the coeliac syndrome
}

\author{
P. B. COTTON \\ M.D. M.R.C.P. \\ Gastrointestinal Laboratory \\ St Thomas' Hospital London S.E.1
}

\section{Summary}

Rapid absorption of whisky has been demonstrated in subjects who had undergone partial gastrectomy or vagotomy and pyloroplasty. Delayed absorption occurred in patients with the coeliac syndrome. These facts are of social and possibly legal significance.

RECENT legislation on road safety has increased the practical significance of blood ethanol levels, which can now be measured with ease and accuracy. For a given dose, peak ethanol levels depend mainly on the rapidity of absorption since the rate of ethanol metabolism is fairly constant (Camps, 1968). Because ethanol is more readily absorbed from the small intestine than from the stomach, the overall absorption rate is largely determined by the rate of gastric emptying (Cori, Villiaume \& Cori, 1930; Haggard, Greenberg \& Lolli, 1941). Gastric emptying is influenced by the quantity and strength of ethanol and the circumstances of its ingestion, both dietary and emotional (Camps, 1968). Emptying may be markedly altered by gastric surgery and we considered that it would be useful to investigate blood ethanol levels after drinking a standard dose of whisky in patients who had previously undergone operations for peptic ulcer. Patients with the coeliac syndrome, in whom reduced ethanol absorption might be expected, were also studied.

\section{Methods}

There were four groups of volunteers. Heavy drinkers were excluded.

(1) Controls. Eleven healthy hospital staff (six men, five women) aged 20-60, mean 42 years.

(2) Partial gastrectomy (Billroth II). Eight men aged 38-64, mean 55 years.

(3) Truncal vagotomy and pyloroplasty. Six men aged $20-49$, mean 40 years.

(4) Coeliac syndrome. Seven patients (three men, four women) aged 35-63, mean 40 years.

The patients with coeliac syndrome were untreated or in relapse; the other patients were all studied at least 6 months after surgery.

\author{
G. WALKER \\ M.R.C.P., M.C.Path. \\ Department of Chemical Pathology \\ St Thomas' Hospital Medical School
}

After a 4-hr fast, subjects rapidly drank Haig Scotch Whisky $\left(70^{\circ}\right.$ proof) in a dose of $1 \mathrm{ml} / \mathrm{kg}$, diluted in the same volume of water. Venous blood was taken into fluoride tubes at 5,10,15,20,30 and $45 \mathrm{~min}$. Blood ethanol was measured by the gas chromatographic method of Curry, Walker \& Simpson (1966).

\section{Results}

Details are given in the Table 1 and Fig. 1. Blood ethanol responses showed considerable individual variation, not least in the control group in which levels at $15 \mathrm{~min}$ ranged from 19 to $95 \mathrm{mg} / 100 \mathrm{ml}$.

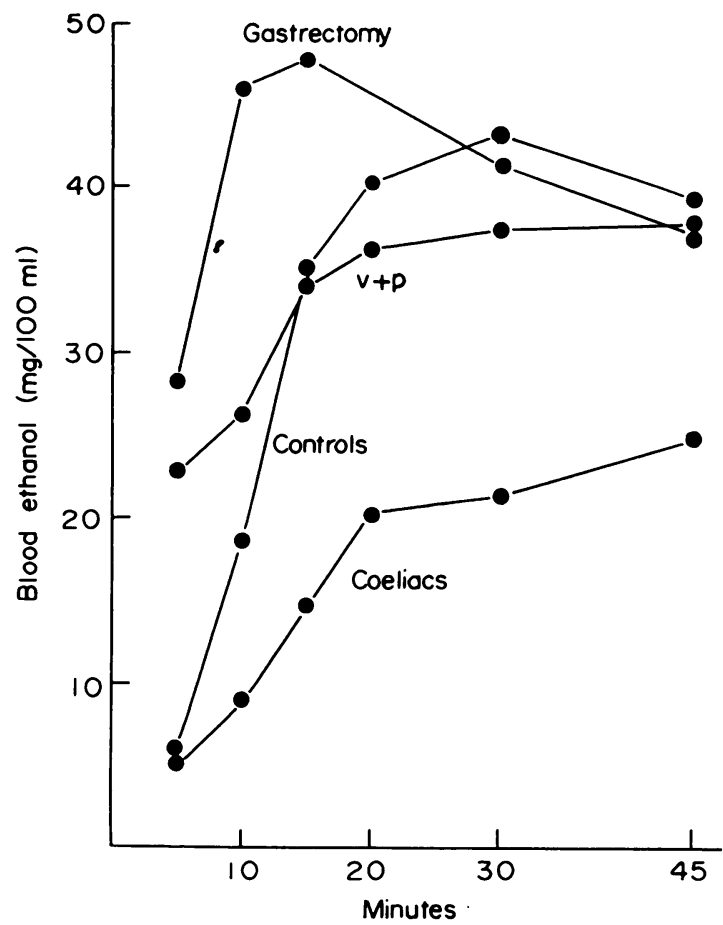

FIG. 1. Mean blood ethanol levels in the four groups of subjects at time intervals after drinking. $v+p$, Vagotomy and pyloroplasty. 
TABLE 1. Mean ( \pm SD) blood levels of ethanol $(\mathrm{mg} / 100 \mathrm{ml})$ at intervals after ethanol ingestion

\begin{tabular}{rcccc}
\hline $\begin{array}{c}\text { Time } \\
(\mathrm{min})\end{array}$ & Controls & Coeliacs & $\begin{array}{c}\text { Billroth II } \\
\text { gastrectomy }\end{array}$ & $\begin{array}{l}\text { Vagotomy+ } \\
\text { pyloroplasty }\end{array}$ \\
\hline 5 & $5 \cdot 0(5 \cdot 4)$ & $5 \cdot 9(3 \cdot 7)$ & $28 \cdot 1(19 \cdot 3)$ & $22 \cdot 8(15 \cdot 1)$ \\
10 & $18 \cdot 5(10 \cdot 8)$ & $8 \cdot 8(4 \cdot 8)$ & $46 \cdot 1(11 \cdot 8)$ & $26 \cdot 3(21.5)$ \\
15 & $35 \cdot 5(23 \cdot 4)$ & $14 \cdot 7(4 \cdot 7)$ & $47 \cdot 8(13 \cdot 3)$ & $34 \cdot 3(17 \cdot 3)$ \\
20 & $40 \cdot 4(22 \cdot 5)$ & $20 \cdot 2(8 \cdot 4)$ & $46 \cdot 3(8 \cdot 4)$ & $36 \cdot 2(14 \cdot 2)$ \\
30 & $43 \cdot 2(15 \cdot 5)$ & $21 \cdot 0(10 \cdot 9)$ & $41 \cdot 3(7 \cdot 1)$ & $37 \cdot 8(14 \cdot 0)$ \\
45 & $39 \cdot 3(11 \cdot 4)$ & $24 \cdot 9(17 \cdot 2)$ & $37 \cdot 6(8 \cdot 7)$ & $37 \cdot 7(11 \cdot 6)$ \\
\hline
\end{tabular}

The results of the coeliac patients were the least variable.

The magnitude of individual variations reduced the likelihood of finding any statistical difference between these small test groups. However, using the ' $t$ ' test, mean ethanol levels were shown to be significantly different from the controls in:

(1) The partial gastrectomy group at 5 and $10 \min (P \leqslant 0.01)$.

(2) The vagotomy and pyloroplasty group at 5 min $(P \leqslant 0 \cdot 01)$.

(3) The coeliac patients at $15 \min (P \leqslant 0.05)$, $30 \mathrm{~min}(P \leqslant 0.01)$ and $45 \mathrm{~min}(P \leqslant 0.05)$.

\section{Discussion}

The significantly flatter absorption curves in the coeliac patients could be the result of slower gastric emptying, reduced intestinal absorption or increased metabolism. Patients with diseased duodenal mucosa might be expected to show abnormalities resulting from malfunction of duodenal receptor mechanisms, including those involved in the control of gastric emptying, and from impaired release of duodenal hormones. Lack of cholecystokinin has been postulated in coeliac disease (Low-Beer et al., 1971), but no evidence is available regarding gastric emptying patterns.

Elmslie et al. (1964) studied ethanol absorption in a small group of patients following Billroth $I$ and Billroth II gastrectomies, using a larger dose ( $1 \mathrm{ml} / \mathrm{kg}$ of $86^{\circ}$ proof whisky). Serum levels peaked significantly higher and earlier than in controls after both operations. However, serum ethanol levels in the control subjects reached a much later and lower peak than in the present series (possibly due to the use of a higher ethanol concentration), which accentuated the difference between patients and $\vec{\omega}$ control subjects.

The shape of the absorption curves in the operated subjects are consistent with current knowledge of gastric-emptying patterns. Emptying is normally rapid after Billroth II gastrectomy, whereas patients who have undergone vagotomy and pyloroplasty are known to have a rapid early emptying phase, followed by a more normal pattern (Colmer, 1972; 은 Cobb et al., 1971).

It is reasonable for surgeons to warn their patients that gastric resection may impair their tolerance of alcohol.

\section{References}

CAMPS, F.E. (1968) Alcohol. Journal of the Royal Collegr of Physicians, 2, 311.

CobB, J.S., Bank, S., Marks, I.N. \& Louw, J.H. (1977) Gastric emptying after vagotomy and pyloroplasty. Digestive Diseases, 16, 207.

Colmer, M.R. (1972) Gastric emptying after gastric operations. Proceedings of the Royal Society of Medicine, 65, 170.

Cori, C.F., Villiaume, E.L. \& CoRi, G.T. (1930) Studies on intestinal absorption. Journal Biological Chemistry, 87, 19.

Curry, A.S., Walker, G.W. \& Simpson, G.S. (1966) Determination of ethanol in blood by gas chromatography. Analyst, 91, 742.

Elmslie, R.G., Davis, R.A., Magee, D.F. \& White, T.T. (1964) Absorption of alcohol after gastrectomy. Surgery, Gynaecology and Obstetrics, 119, 1256.

HagGaRD, H.W., GreenberG, L.A. \& Lolli, G. (1941) Alcohol absorption, with special reference to influence on concentration of alcohol appearing in blood. Quarterly Journal of the Study of Alcohol, 1, 684.

Low-Beer, T.S., Heaton, K.W., Heaton, S.T. \& Read, A.E. (1971) Gall bladder inertia and sluggish enterohepatic circulation of bile salts in coeliac disease. Lancet, i, 991 . 